\title{
The Eternal Dilemma: Fat-poor Angiomyolipoma
}

\section{Ezeli İkilem: Yağdan Fakir Anjiomyolipom}

\section{Omer Yildiz®, Mustafa Orhan Nalbant®, Elif Hocaoglu®, Ercan Inci®}

Department of Radiology, University of Health Sciences, Dr. Sadi Konuk Training and Research Hospital, Istanbul, Turkey

Cite as: Yildiz O, Nalbant MO, Hocaoglu E, Inci E.

The eternal dilemma; fat-poor angiomyolipoma. Grand J Urol 2021;1(3):150-1.

Submission date: 23 February 2021

Acceptance date: 16 March 2021

Online First: 31 March 2021

Publication date: 20 September 2021

Corresponding Author: Omer Yildiz / University of Health Sciences, Dr. Sadi Konuk Training and Research Hospital, Department of Radiology, Bakirkoy, Istanbul, Turkey / yildiz_omer@outlook.com ORCID ID: 0000-0003-4774-9281

A 55-year-old female patient admitted to the emergency department with one week long abdominal pain. In the physical examination of the patient, no clinical finding other than sensitivity was observed. The laboratory tests were normal. Because there was discordance between the patients clinical findings and laboratory tests, ultrasound exam was performed to exclude acute abdomen and a mass was detected in the anterior of left kidney's upper pole. There upon, the patient was discharged with recommendations and directed to the urology department. The patient had no history of malignancy or surgical history. Contrast enhanced abdominal magnetic resonance (MR) was performed for the lesion characterization. In the abdominal MRI, a lesion was detected in the anterior region of the left kidney's upper pole which is $36 \times 20 \mathrm{~mm}$ in size. The lesion was hypointense on T2 weighted images (WI), slightly hyperintense on T1WI and had central cystic area. Since the mass was closely adjacent to the tail of the pancreas and had similar signal intensity with the pancreas on $\mathrm{T} 2 \mathrm{WI}$ and postcontrast images, the origin of the lesion could not be made clearly between left kidney and pancreatic tail (Figure 1-5). Therefore, histopathologic verification was recommended for preoperative management. It was reported as angiomyolipoma, wihch is rich in smooth muscle and poor in fat, after staining with actin and HMB-45 along with immunohistochemical staining obtained as a result of the biopsy procedure.

Renal angiomyolipomas are the most common benign kidney tumors. Non invasive diagnostic capacity between benign and malignant lesions is not yet at the desired standard. Approximately $10-17 \%$ of the resected kidney tumors are benign, and $2-6 \%$ of them are reported as angiomyolipomas [1]. Angiomyolipomas contain smooth muscle tissue, blood vessels and macroscopic fat areas in varying proportions [2]. In most cases, it is diagnosed radiologically without any further examination due to the macroscopic fat content. In the radiological diagnosis of angiomyolipoma, we use findings such as containing densities below $-10 \mathrm{HU}$ in computerized tomography (CT) examination

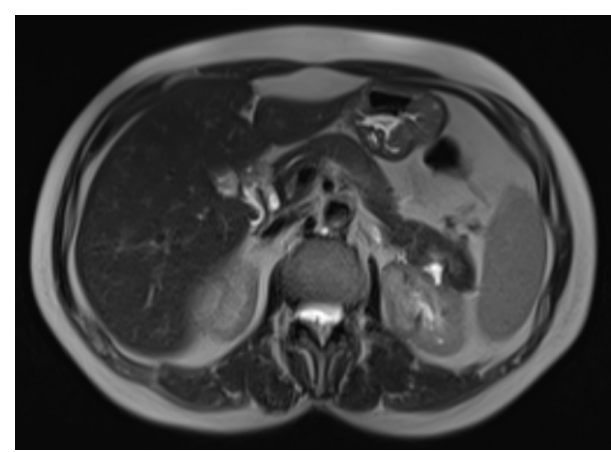

Figure 1. Axial T2 weighted (Contrast-enhanced abdominal magnetic resonance images of the patient)

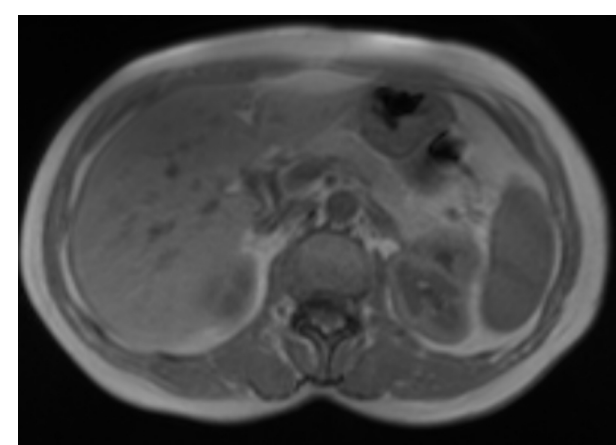

Figure 2. In phase (Contrast-enhanced abdominal magnetic resonance images of the patient)

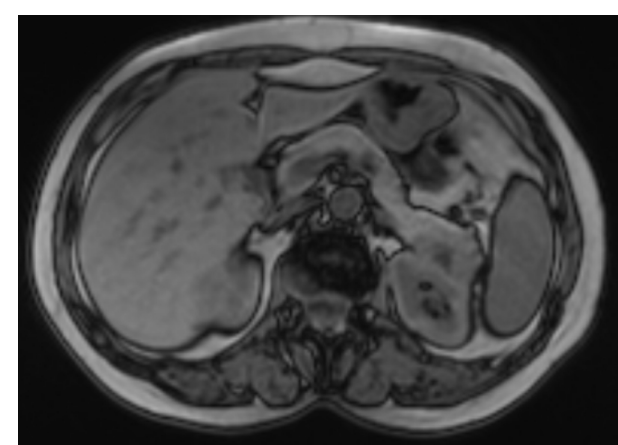

Figure 3. Out of phase (Contrast-enhanced abdominal magnetic resonance images of the patient)

ORCID ID: M.O. Nalbant 0000-0002-5277-9111 E. Hocaoglu 0000-0002-2506-4794 

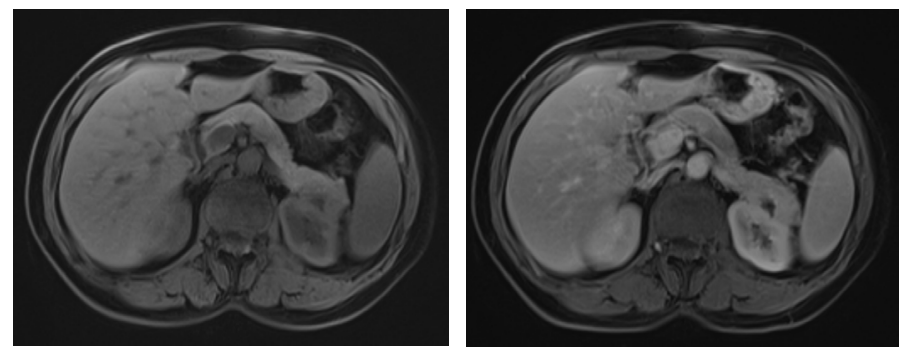

Figure 4. T1 Weighted, fat saturated T1 Figure 5. Post contrast images reveaweighted (Contrast-enhanced abdominal led a solid mass with central cystic area magnetic resonance images of the patient) (Contrast-enhanced abdominal magnetic resonance images of the patient)

or showing suppression in fat saturated sequences in MRI [3]. In addition, chemical shift suppression techniques are useful in MRI in cases when there is a small amount of fatty tissue [4]. On the other hand, in $4.5 \%$ of angiomyolipomas, fatty tissue may not be seen radiologically [5]. Since the imaging findings of these fat-poor lesions, containing less than $25 \%$ fat, cannot be distinguished from RCC and they pose a serious problem [6]. RCCs, especially clear cell carcinomas, may also contain fat, but unlike angiomyolipomas, this adipose tissue is located at intracellular space and we use signal loss in out of phase MR sequence to differentiate RCC from angiomyolipoma [7]. Angiomyolipomas carry the risk of bleeding, especially in sizes over $4 \mathrm{~cm}$ and sometimes, fat densities can be overlooked due to intralesional bleeding and they can be confused with RCC [8]. Although new methods such as CT histogram [9] and specific MR sequences $[4,10]$ have been used in the separation of fatpoor angiomyolipoma and RCC with new developments in radiology and technology, the application and reliability of these methods in daily practice are not sufficient.

Keywords: angiomyolipoma, renal cell cancer, chemical chift imaging

Ethics Committee Approval: N/A.

Informed Consent: An informed consent was obtained from the patient.

Publication: The results of the study were not published in ful lor in part in form of abstracts.

Peer-review: Externally peer-reviewed.

Conflict of Interest: The authors declare that they have no conflict of interests.

Financial Disclosure: The authors declare that this study received no financial support.

\section{References}

[1] Fujii Y, Komai Y, Saito K, Iimura Y, Yonese J, Kawakami $\mathrm{S}$, et al. Incidence of Benign Pathologic Lesions at Partial Nephrectomy for Presumed RCC Renal Masses: Japanese Dual-Center Experience with 176 Consecutive Patients. Urology 2008;72:598-602. https://doi.org/10.1016/j.urology.2008.04.054.

[2] Hindman N, Ngo L, Genega EM, Melamed J, Wei J, Braza $\mathrm{JM}$, et al. Angiomyolipoma with minimal fat: Can it be differentiated from clear cell renal cell carcinoma by using standard MR techniques? Radiology 2012;265:468-77. https://doi.org/10.1148/radiol.12112087.

[3] Davenport MS, Neville AM, Ellis JH, Cohan RH, Chaudhry HS, Leder RA. Diagnosis of renal angiomyolipoma with hounsfield unit thresholds: Effect of size of region of interest and nephrographic phase imaging. Radiology 2011;260:158-65. https://doi.org/10.1148/radiol.11102476.

[4] Kim JK, Kim SH, Jang YJ, Ahn H, Kim CS, Park H, et al. Renal angiomyolipoma with minimal fat: Differentiation from other neoplasms at double-echo chemical shift FLASH MR imaging. Radiology 2006;239:174-80. https://doi.org/10.1148/radiol.2391050102.

[5] Yang CW, Shen SH, Chang YH, Chung HJ, Wang JH, Lin ATL, et al. Are there useful CT features to differentiate renal cell carcinoma from lipid-poor renal angiomyolipoma? Am J Roentgenol 2013;201:1017-28. https://doi.org/10.2214/AJR.12.10204.

[6] Milner J, McNeil B, Alioto J, Proud K, Rubinas T, Picken $\mathrm{M}$, et al. Fat Poor Renal Angiomyolipoma: Patient, Computerized Tomography and Histological Findings. J Urol 2006;176:905-9. https://doi.org/10.1016/j.juro.2006.04.016.

[7] Schieda N, Davenport MS, Pedrosa I, Shinagare A, Chandarana $\mathrm{H}$, Curci $\mathrm{N}$, et al. Renal and adrenal masses containing fat at MRI: Proposed nomenclature by the society of abdominal radiology disease-focused panel on renal cell carcinoma. J Magn Reson Imaging 2019;49:917-26. https://doi.org/10.1002/jmri.26542.

[8] Jinzaki M, Silverman SG, Akita H, Mikami S, Oya M. Diagnosis of Renal Angiomyolipomas: Classic, FatPoor, and Epithelioid Types. Semin Ultrasound, CT MRI 2017;38:37-46. https://doi.org/10.1053/j.sult.2016.11.001.

[9] Chaudhry HS, Davenport MS, Nieman CM, Ho LM, Neville AM. Histogram analysis of small solid renal masses: Differentiating minimal fat angiomyolipoma from renal cell carcinoma. Am J Roentgenol 2012;198:377-83. https://doi.org/10.2214/AJR.11.6887.

[10] Tanaka H, Yoshida S, Fujii Y, Ishii C, Tanaka H, Koga F, et al. Diffusion-weighted magnetic resonance imaging in the differentiation of angiomyolipoma with minimal fat from clear cell renal cell carcinoma. Int J Urol 2011;18:727-30. https://doi.org/10.1111/j.1442-2042.2011.02824.x. 